\title{
EVALUASI IMPLEMENTASI SISTEM MANAJEMEN KESELAMATAN DAN KESEHATAN KERJA DAN UPAYA PERBAIKAN DENGAN METODE HIRADC (STUDI KASUS DI PERUSAHAAN INJECTION MOLDING TANGERANG)
}

\author{
${ }^{1 \cdot}$ Hartono, ${ }^{2}$ Tina Hernawati \\ 1,2. Program Studi Teknik Industri, Fakultas Teknik \\ Universitas Muhammadiyah Tangerang \\ Jl. Perintis Kemerdekaan I/33, Cikokol, Kota Tangerang \\ Email : ${ }^{1}$ hartono@umt.ac.id, ${ }^{2}$ tinahernawati@umt.ac.id
}

\begin{abstract}
A b s trak
Manajemen Keselamatan dan Kesehatan Kerja sudah ada secara global maupun di Indonesia, namun pada pelaksanaannya masih banyak terjadi kecelakaan dan penyakit akibat kerja, di Perusahaan Injection Molding Tangerang juga masih terdapat kecelakaan meskipun manajemen K3 sudah berjalan. Tujuan penelitian ini untuk mengevaluasi Sistem Manajemen Keselamatan dan Kesehatan Kerja di departemen Painting dan mengetahui perbaikan SMK3 di departemen Painting Perusahaan Injection Molding Tangerang. Metode yang di pakai adalah menggunakan HIRADC (Hazard Identification Risk Assesment and Determaining Control) yang terdiri dari identifikasi masalah, penilaian resiko dan pengendalian resiko. Hasil penelitian dari sembilan proses yang ada di departemen Painting, proses yang paling kecil kemungkinan resiko kecelakaannya adalah proses cleaning dan finishing dan proses dengan kemungkinan resiko paling besar adalah proses perawatan sprayboth dan setelah dilakukan perbaikan HIRADC dan perbaikan lapangan dapat diketahui pada tahun selanjutnya (2017) angka kecelakaan kerja di departemen Painting mengalami penurunan.
\end{abstract}

Kata Kunci : K3, hazard identification, risk assessment, determining control.

\section{PENDAHULUAN}

Berdasarkan data International Labour Organization (ILO) tahun 2013, 1 pekerja di dunia meninggal setiap 15 detik karena kecelakaan kerja dan 160 pekerja mengalami sakit akibat kerja. Tahun sebelumnya (2012) ILO mencatatat angka kematian dikarenakan kecelakaan dan penyakit akibat kerja (PAK) sebanyak 2 juta kasus setiap tahun. Di Indonesia sendiri, berdasarkan data Badan Penyelenggara Jaminan Sosial (BPJS) Ketenagakerjaan di Indonesia telah terjadi 105.182 kasus kecelakaan kerja sampai akhir tahun 2015. Di mana 2.375 kasus dari total jumlah kecelakaan kerja ialah kasus kecelakaan berat yang menyebabkan kematian. Angka kecelakaan kerja itu relatif sangat tinggi. Untuk menjawab tantangan tersebut Pemerintah Indonesia yang diwakili oleh Departemen Tenaga Kerja dan Transmigrasi telah menetapkan sebuah peraturan perundangan mengenai Sistem Manajemen Keselamatan dan Kesehatan Kerja (SMK3) yang tertuang dalam Peraturan Menteri Tenaga Kerja Nomor : PER.05/MEN/1996. Penerapan K3 memiliki beberapa tujuan, dalam pelaksanaannya berdasarkan Undang-Undang No 1 Tahun 1970 yaitu melindungi dan menjamin keselamatan setiap tenaga kerja dan orang lain di tempat kerja, menjamin setiap sumber produksi dapat digunakan secara aman dan efisien dan meningkatkan kesejahteraan dan produktivitas Nasional.

Berdasarkan peraturan dari pemerintah tersebut maka Perusahaan plastik injection molding di Tangerang juga menerapkan Sistem Manajemen Keselamatan dan Kesehatan Kerja di dalam perusahaan secara menyeluruh. Salah satu departemen yang mempunyai resiko kecelakaan 
dan penyakit akibat kerja yang tinggi di perusahaan ini adalah departemen painting. Terakhir di tahun 2016 terdapat 3 angka kecelakaan yang tercatat.

OHSAS 18001 (2007) mendefinisikan keselamatan dan kesehatan kerja sebagai kondisi dan faktor yang mempengaruhi atau akan mempengaruhi keselamatan dan kesehatan pekerja dan juga tamu atau orang lain berada di tempat kerja. HIRADC (Hazzard Identification Risk Assesment and Determaining Control) adalah salah satu bagian dari standar OHSAS 18001;2008 clause 4.3.1, Di indonesia biasa juga disebut sebagai risk assesment atau identifikasi bahaya dan aspek K3L. Pada klausa itu menyebutkan bahwa organisasi harus menetapkan, membuat, menerapkan dan memelihara prosedur untuk melakukan identifikasi bahaya, penilaian risiko dan menentukan pengendalian bahaya dan risiko yang diperlukan. Identifikasi Bahaya, Penilaian Resiko dan Pengendalian Resiko merupakan salah satu syarat elemen Sistem Manajemen Keselamatan Kerja OHSAS 18001:2008 klausul 4.3.1. Mathis dan Jackson (2012) mendefinisikan keselamatan sebagai perlindungan terhadap kesejahteraan fisik seseorang. Mangkunegara (2014) mendefinisikan keselamatan kerja sebagai kondisi yang aman atau selamat dari penderitaan, kerusakan atau kerugian di tempat kerja. Dari beberapa pengertian di atas dapat disimpulkan bahwa perlindungan terhadap fisik seseorang yang aman atau selamat dari penderitaan, kerusakan atau kerugian di tempat kerja.

\section{METODE PENELITIAN}

Untuk melakukan penelitian guna mendapatkan tujuan yang diinginkan maka dilakukan beberapa langkah-langkah sebagai berikut:

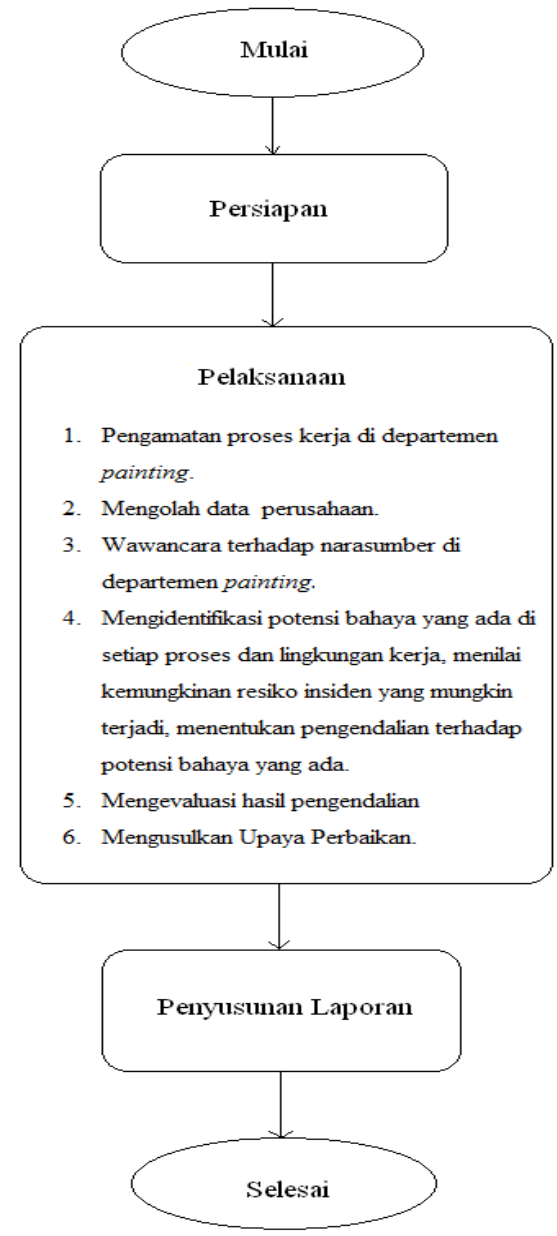

Gambar 1. Aliran Langkah-langkah Penelitian 


\section{HASIL DAN PEMBAHASAN}

Dalam kegiatan produksi di Departemen Painting, keselamatan dan kesehatan kerja memiliki peranan penting agar kecelakan dalam kegiatan produksi dapat dicegah sedini mungkin, agar hal-hal yang tidak di inginkan tidak terjadi di dalam proses produksi sehingga jalannya proses produksi sesuai dengan rencana. Maka dari itu untuk mencapai implementasi SMK3 yang maksimal di departemen Painting pihak manajemen perusahaan mengevaluasi dan melakukan upaya perbaikan. Upaya perbaikan Sistem manajamen keselamatan dan kesehatan kerja menggunakan metode HIRADC. Berikut adalah proses pengecatan Helm di departemen Painting :

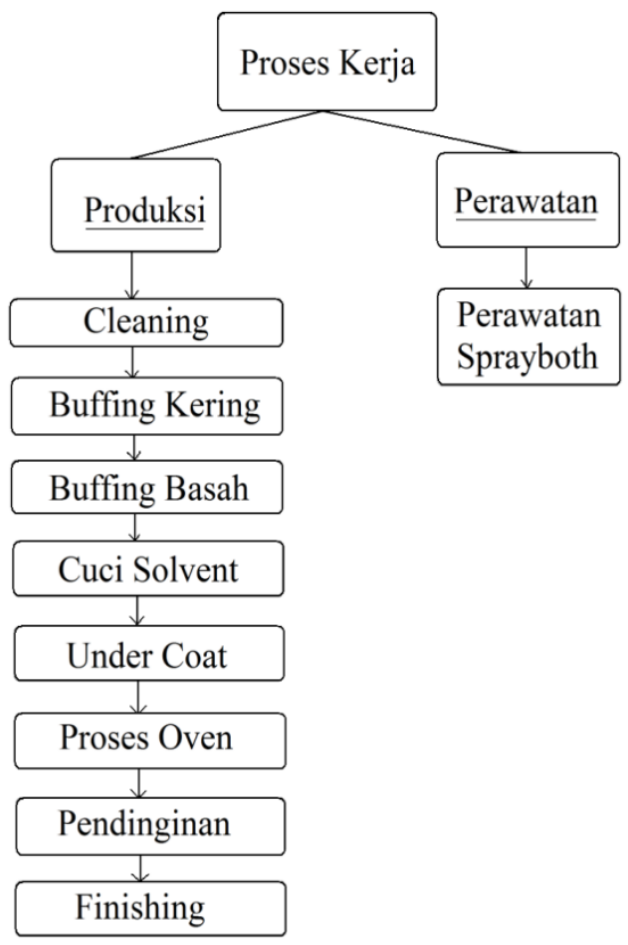

Gambar 2 Flow Chart Proses Kerja Bagian Painting

Setelah dilakukan penelitian Sistem Manajemen Keselamatan dan Kesehatan Kerja di Perusahaan Injection Molding Tangerang maka dapat dievaluasi dengan cara membandingkan antara peraturan dan pelaksanaan pekerjaan di lapangan diantaranya sebagai berikut :

Tabel 1 Identifikasi Bahaya Bagian Painting

\begin{tabular}{|c|c|c|c|c|c|}
\hline No & Nama Kegiatan & Kondisi & Sumber Bahaya & Jenis Bahaya & Resiko/Dampak \\
\hline 1 & Cleaning & Normal & Conveyor & Mekanis & - Terjepit \\
\hline 2 & Buffing Kering & Normal & Putaran amplas & Mekanis & $\begin{array}{ll}\text { - } & \text { Tergores } \\
\text { - } & \text { Terbentur } \\
\text { - } & \text { Tersengat listrik }\end{array}$ \\
\hline 3 & Buffing Basah & Normal & Putaran amplas & Mekanis & $\begin{array}{ll}\text { - } & \text { Tergores } \\
\text { - } & \text { Terbentur } \\
\text { - } & \text { Tersengat listrik }\end{array}$ \\
\hline 4 & Cuci solvent & Normal & Asap cat & Kimiawi & - Gangguan pernafasan \\
\hline & & & Asap cat & Kimiawi & - Iritasi kulit/mata \\
\hline 5 & Under coat & Normal & Asap cat & Kimiawi & - Gangguan pernafasan \\
\hline
\end{tabular}




\begin{tabular}{|c|c|c|c|c|c|}
\hline & & & Putaran jig & Mekanis & $\begin{array}{ll}\text { - } & \text { Tergores } \\
\text { - } & \text { Terbentur }\end{array}$ \\
\hline 6 & Oven & Normal & Suhu panas & Fisik & - Luka bakar Dehidrasi \\
\hline 7 & Pendinginan & Normal & Material panas & Fisik & - Luka bakar \\
\hline 8 & Finishing & Normal & Conveyor & Mekanis & - Terjepit \\
\hline \multirow{3}{*}{9} & \multirow{3}{*}{$\begin{array}{l}\text { Perawatan } \\
\text { Sprayboth }\end{array}$} & \multirow{3}{*}{ Normal } & Ketinggian & Fisik & $\begin{array}{ll}\text { - Jatuh } \\
\text { - Meninggal }\end{array}$ \\
\hline & & & Berdebu & Fisik & $\begin{array}{l}\text { - } \text { Iritasi kulit/mata } \\
\text { - } \text { Gangguan pernafasan }\end{array}$ \\
\hline & & & Listrik & Listrik & $\begin{array}{l}\text { - Tersengat listrik } \\
\text { - Meninggal }\end{array}$ \\
\hline
\end{tabular}

Berdasarkan hasil identifikasi risiko diatas dilanjutkan dengan penilian risiko. Penilaian resiko adalah proses penilaian dari kegiatan-kegiatan identifikasi bahaya yang telah dilakukan sebelumnya. Penilaian risiko dilakukan dengan memberikan penilaian terhadap tingkat parahnya dampak yang diakibatkan (severity), seringnya penyebab potensi bahaya terjadi (Occurance). Di dalam menentukan nilai-nilai yang tepat dan sama untuk semua area, dibuat suatu skala-skala yang telah ditetapkan.

Skala untuk penilaian tingkat keparahan dampak yang diakibatkan (severity) dilakukan berdasarkan keparahan secara fisik dan keparahan secara materi. Dua definisi dilakukan dengan dasar yang berbeda namun memiliki hubungan terkait. Hubungan tersebut adalah nilai dari keparahan secara fisik yang berhubungan dengan kerugian yang dialami perusahaan. Sedangkan skala penilaian keseringan penyebab potensi bahaya terjadi (Occurance) dibuat berdasarkan berapa kali suatu aktivitas penyebab bahaya dilakukan dan kondisi penyebab bahaya terjadi.

Tabel 2 Penilaian Resiko Bagian Painting

\begin{tabular}{|c|c|c|c|c|c|c|c|}
\hline No & Nama Kegiatan & $\begin{array}{l}\text { Sumber } \\
\text { Bahaya }\end{array}$ & Resiko/ Dampak & $\mathbf{O}$ & $\mathbf{S}$ & Matrix & $\begin{array}{c}\text { Tingkat } \\
\text { Resiko }\end{array}$ \\
\hline 1 & Cleaning & Conveyor & - Terjepit & 2 & 2 & & Rendah \\
\hline 2 & Buffing Kering & Putaran amplas & $\begin{array}{ll}\text { - } & \text { Tergores } \\
\text { - } & \text { Terbentur } \\
\text { - } & \text { Tersengat listrik }\end{array}$ & 4 & 4 & & Tinggi \\
\hline 3 & Buffing Basah & Putaran amplas & $\begin{array}{ll}\text { - } & \text { Tergores } \\
\text { - } & \text { Terbentur } \\
\text { - } & \text { Tersengat listrik }\end{array}$ & 4 & 4 & & Tinggi \\
\hline 4 & Cuci solvent & Asap cat & - Gangguan pernafasan & 4 & 2 & & Sedang \\
\hline \multirow{3}{*}{5} & \multirow{3}{*}{ Under coat } & Asap cat & - Iritasi kulit/mata & 4 & 2 & & Sedang \\
\hline & & Asap cat & - Gangguan pernafasan & 4 & 2 & & Sedang \\
\hline & & Putaran jig & $\begin{array}{ll}\text { - } & \text { Tergores } \\
\text { - } & \text { Terbentur }\end{array}$ & 4 & 2 & & Sedang \\
\hline 6 & Oven & Suhu panas & $\begin{array}{ll}\text { - } & \text { Luka bakar } \\
\text { - } & \text { Dehidrasi }\end{array}$ & 3 & 3 & & Sedang \\
\hline
\end{tabular}




\begin{tabular}{|c|c|c|c|c|c|c|}
\hline 7 & Pendinginan & Material panas & - Luka bakar & 3 & 4 & Tinggi \\
\hline 8 & Finishing & Conveyor & - Terjepit & 2 & 2 & \\
\hline \multirow{4}{*}{9} & \multirow{4}{*}{$\begin{array}{l}\text { Perawatan } \\
\text { Sprayboth }\end{array}$} & Ketinggian & $\begin{array}{ll}\text { - } & \text { Jatuh } \\
\text { - } & \text { Meninggal } \\
\end{array}$ & 4 & 5 & Extrim \\
\hline & & Berdebu & - Iritasi kulit/mata & 3 & 2 & Rendah \\
\hline & & & - Pernafasan & & & \\
\hline & & Listrik & $\begin{array}{ll}\text { - } & \text { Tersengat } \\
\text { - } & \text { Meninggal }\end{array}$ & 4 & 4 & Tinggi \\
\hline
\end{tabular}

Hasil dari penilaian risiko pada tabel 2 dapat diketahui risiko-risiko yang memiliki tingkatan rendah, sedang, dan tinggi. Tingkatan risiko tersebut sebagai acuan perusahaan untuk melakukan tindakan pengendalian risiko. Berikut ini merupakan pengendalian risiko yang telah ditetapkan.

Tabel 3 Pengendalian Resiko

\begin{tabular}{|c|c|c|c|c|}
\hline No & Nama Kegiatan & Sumber Bahaya & Resiko/Dampak & Pengendalian Resiko \\
\hline 1 & Cleaning & Conveyor & - Terjepit & $\begin{array}{l}\text { a. Rambu K3 } \\
\text { b. SOP }\end{array}$ \\
\hline 2 & Buffing Kering & Putaran amplas & $\begin{array}{ll}\text { - } & \text { Tergores } \\
\text { - } & \text { Terbentur } \\
\text { - } & \text { Tersengat listrik }\end{array}$ & $\begin{array}{l}\text { a. Rambu K3 } \\
\text { b. Safety Training } \\
\text { c. Sarung tangan } \\
\text { d. SOP } \\
\text { e. Chek sheet }\end{array}$ \\
\hline 3 & Buffing Basah & Putaran amplas & $\begin{array}{ll}\text { - } & \text { Tergores } \\
\text { - } & \text { Terbentur } \\
\text { - } & \text { Tersengat listrik }\end{array}$ & $\begin{array}{l}\text { a. Rambu K3 } \\
\text { b. Safety Training } \\
\text { c. Sarung tangan } \\
\text { d. SOP } \\
\text { e. Chek sheet }\end{array}$ \\
\hline 4 & Cuci solvent & Asap cat & $\begin{array}{l}\text { - Gangguan } \\
\text { pernafasan }\end{array}$ & $\begin{array}{ll}\text { a. } & \text { Rambu K3 } \\
\text { b. } & \text { Respirator }\end{array}$ \\
\hline \multirow{3}{*}{5} & \multirow{3}{*}{ Under coat } & Asap cat & - Iritasi kulit/mata & $\begin{array}{ll}\text { a. } & \text { Rambu K3 } \\
\text { b. } & \text { Safety Glasses }\end{array}$ \\
\hline & & Asap cat & $\begin{array}{l}\text { - Gangguan } \\
\text { pernafasan }\end{array}$ & $\begin{array}{ll}\text { a. } & \text { Rambu K3 } \\
\text { b. } & \text { Respirator }\end{array}$ \\
\hline & & Putaran jig & $\begin{array}{ll}\text { - } & \text { Tergores } \\
\text { - } & \text { Terbentur }\end{array}$ & $\begin{array}{ll}\text { a. } & \text { Rambu K3 } \\
\text { b. } & \text { Safety Training } \\
\text { c. } & \text { SOP } \\
\text { d. } & \text { Check sheet }\end{array}$ \\
\hline 6 & Oven & Suhu panas & $\begin{array}{ll}\text { - } & \text { Luka bakar } \\
\text { - } & \text { Dehidrasi }\end{array}$ & $\begin{array}{ll}\text { a. } & \text { Rambu K3 } \\
\text { b. Safety Training } \\
\text { c. Sarung tangan } \\
\text { d. SOP } \\
\text { e. } \text { Chek sheet }\end{array}$ \\
\hline 7 & Pendinginan & Material panas & - Luka bakar & $\begin{array}{ll}\text { a. } & \text { Rambu K3 } \\
\text { b. } & \text { Safety Training } \\
\text { c. } & \text { Sarung tangan } \\
\text { d. } & \text { SOP }\end{array}$ \\
\hline
\end{tabular}




\begin{tabular}{|c|c|c|c|c|}
\hline & & & & e. Chek sheet \\
\hline 8 & Finishing & Conveyor & - Terjepit & $\begin{array}{ll}\text { a. } & \text { Rambu K3 } \\
\text { b. } & \text { SOP }\end{array}$ \\
\hline \multirow[t]{4}{*}{9} & \multirow[t]{4}{*}{ Perawatan Sprayboth } & Ketinggian & $\begin{array}{ll}\text { - Jatuh } \\
\text { - } \text { Meninggal }\end{array}$ & $\begin{array}{l}\text { a. Rambu K3 } \\
\text { b. Safety Training } \\
\text { c. Pengawasan }\end{array}$ \\
\hline & & Berdebu & - Iritasi kulit/mata & $\begin{array}{ll}\text { a. } & \text { Rambu K3 } \\
\text { b. } & \text { Safety Glasses } \\
\text { c. Pengawasan } \\
\text { d. SOP }\end{array}$ \\
\hline & & & $\begin{array}{l}\text { - Gangguan } \\
\text { pernafasan }\end{array}$ & $\begin{array}{ll}\text { a. } & \text { Rambu K3 } \\
\text { b. } & \text { Respirator } \\
\text { c. } & \text { Pengawasan } \\
\text { d. } & \text { SOP }\end{array}$ \\
\hline & & Listrik & $\begin{array}{l}\text { - Tersengat listrik } \\
\text { - Meninggal }\end{array}$ & $\begin{array}{l}\text { a. Rambu K3 } \\
\text { b. Safety Training } \\
\text { c. Pengawasan } \\
\text { d. SOP } \\
\text { e. Check sheet }\end{array}$ \\
\hline
\end{tabular}

Dengan hasil pembahasan diatas maka dapat diperjelas bahwa tabel HIRADC yang dilakukan di bagian Painting adalah sebagai berikut :

Tabel 4 Tabel HIRADC

\begin{tabular}{|c|c|c|c|c|c|c|c|c|c|c|c|c|c|}
\hline \multirow[b]{2}{*}{ No } & \multicolumn{3}{|c|}{ Potensi Bahaya } & \multicolumn{6}{|c|}{ Penilaian Resiko } & \multirow{2}{*}{$\begin{array}{c}\text { Pengendalian Bahaya } \\
\text { Pengendalian }\end{array}$} & \multicolumn{2}{|c|}{$\begin{array}{c}\text { Hasil } \\
\text { Pemantauan }\end{array}$} & \multirow{2}{*}{ 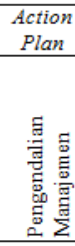 } \\
\hline & Kegiatan & $\begin{array}{l}\text { Sumber } \\
\text { Bahaya }\end{array}$ & Jenis Bahaya & 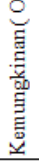 & 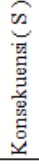 & $\begin{array}{l}\text { 萇 } \\
\text { 焉 }\end{array}$ & 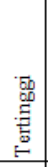 & 哿 & 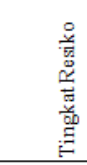 & & 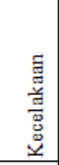 & 岕 & \\
\hline 1 & Cleaning & Conveyor & Mekanis: Terjepit & 2 & 2 & & & $\checkmark$ & Rendah & Rambu K3, SOP & $\checkmark$ & & $\checkmark$ \\
\hline 2 & $\begin{array}{l}\text { Buffing } \\
\text { Kening }\end{array}$ & $\begin{array}{l}\text { Putaran } \\
\text { amplas }\end{array}$ & $\begin{array}{l}\text { Mekanis: Tergores, terbentur, } \\
\text { Tersengat listrik }\end{array}$ & 4 & 4 & & & & Tinggi & $\begin{array}{c}\text { Rambu K3, Safety Training, Sarung tangan, SOP, } \\
\text { Chek sheet }\end{array}$ & $\checkmark$ & & $\checkmark$ \\
\hline 3 & $\begin{array}{l}\text { Buffing } \\
\text { Basah }\end{array}$ & $\begin{array}{l}\text { Putaran } \\
\text { amplas }\end{array}$ & $\begin{array}{l}\text { Mekanis: Tergores, terbentur, } \\
\text { Tersengat listrik }\end{array}$ & 4 & 4 & & & & Tinggi & $\begin{array}{c}\text { Rambu K3, Safety Training, Sarung tangan, SOP, } \\
\text { Chek sheet }\end{array}$ & $\checkmark$ & & $\checkmark$ \\
\hline 4 & Cuci solvent & Asap cat & kimiawi : Gangguan pemafasan & 4 & 2 & & & & Sedang & Rambu K3, Respirator & & $\checkmark$ & $\checkmark$ \\
\hline \multirow[t]{3}{*}{5} & \multirow[t]{3}{*}{ Under coat } & Asap cat & Kimiawi : Iritasi kulit/mata & 4 & 2 & & & & Sedang & Rambu K3, Safety Glasses & & $\checkmark$ & $\checkmark$ \\
\hline & & Asap cat & kimiawi : Gangguan pemafasan & 4 & 2 & & & & Sedang & Rambu K3, Respirator & & $\checkmark$ & $\checkmark$ \\
\hline & & Putaranjig & Mekanis: Tergores, terbentur & 4 & 2 & & & & Sedang & Rambu K3, Safety Training, SOP, Check sheet & $\checkmark$ & & $\checkmark$ \\
\hline 6 & Oven & $\begin{array}{c}\text { Suhu } \\
\text { panas }\end{array}$ & Fisik : Luka bakar, Dehidrasi & 3 & 3 & & & & Sedang & $\begin{array}{c}\text { Rambu K3, Safety Training, Sarung tangan, SOP, } \\
\text { Chek sheet }\end{array}$ & $\checkmark$ & $r$ & $\checkmark$ \\
\hline 7 & Pendinginan & $\begin{array}{c}\text { Material } \\
\text { panas }\end{array}$ & Fisik : Luka bakar & 3 & 4 & & & & Tinggi & $\begin{array}{c}\text { Rambu K3, Safety Training, Sarung tangan, SOP, } \\
\text { Chek sheet }\end{array}$ & $\checkmark$ & & $\checkmark$ \\
\hline 8 & Finishing & Conveyor & Mekanis: Terjepit & 2 & 2 & & & $\checkmark$ & Rendah & Rambu K3, SOP & $r$ & & $\checkmark$ \\
\hline \multirow[t]{4}{*}{9} & \multirow[t]{4}{*}{$\begin{array}{l}\text { Perawatan } \\
\text { Sprayboth }\end{array}$} & Ketinggian & Fisik : Jatuh, Meninggal & 4 & 5 & & $\checkmark$ & & Extrim & $\begin{array}{c}\text { APD, Rambu K3, Safety Training, Pengawasan, } \\
\text { SOP }\end{array}$ & $\checkmark$ & & $\checkmark$ \\
\hline & & Berdebu & Fisik : Iritasi kulit/mata & 3 & 2 & & & & Rendah & Rambu K3, Safety Glasses, Pengawasan, SOP & & $\checkmark$ & $\checkmark$ \\
\hline & & Berdebu & Fisik : Gangguan pemafasan & 3 & 2 & & & & Rendah & Rambu K3, Respirator, Pengawasan, SOP & & $\checkmark$ & $\checkmark$ \\
\hline & & Listrik & $\begin{array}{l}\text { Listrik : Tersengat listrik, } \\
\text { Meninggal }\end{array}$ & 4 & 4 & & & & Tinggi & $\begin{array}{c}\text { Rambu K3, Safety Training, Pengawasan, SOP, } \\
\text { Check sheet }\end{array}$ & $\checkmark$ & & $\checkmark$ \\
\hline
\end{tabular}

Untuk menunjang pelaksanaan perbaikan menggunakan HIRADC juga diusulkan beberapa upaya perbaikan di lingkungan tempat kerja di setiap proses di departemen Painting. Berikut adalah usulan perbaikan untuk bagian Painting: 
Tabel 5 Upaya Perbaikan di Lapangan

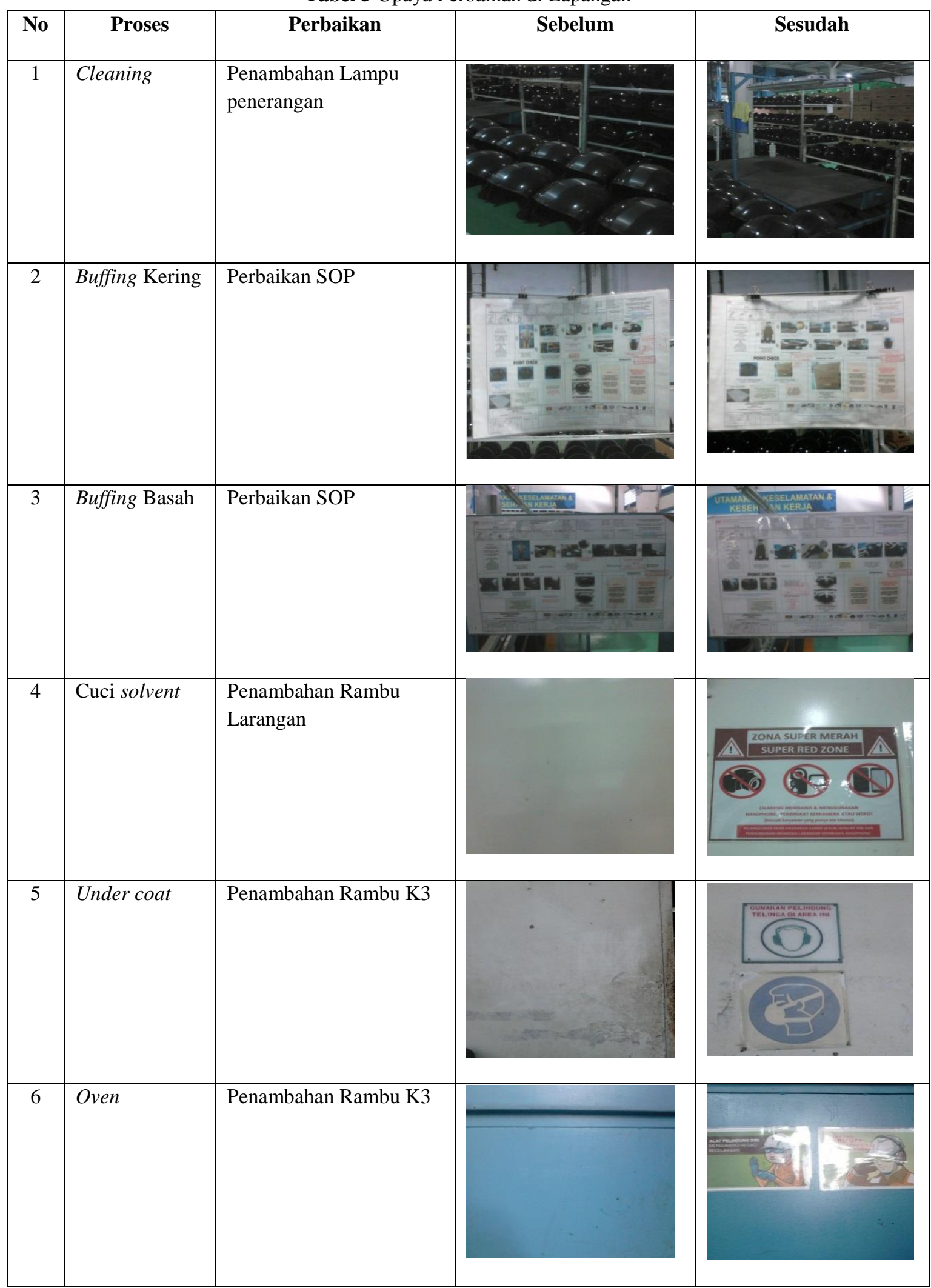




\begin{tabular}{|c|l|l|l|l|}
\hline 7 & Pendinginan & $\begin{array}{l}\text { Pengecatan Lantai area } \\
\text { rak Helm }\end{array}$ & $\begin{array}{l}\text { Penggantian Lampu } \\
\text { penerangan ke LED }\end{array}$ \\
\hline 8 & Finishing & $\begin{array}{l}\text { Penambahan Step nosing } \\
\text { pada tangga sprayboth }\end{array}$ & $\begin{array}{l}\text { Perawatan } \\
\text { Sprayboth }\end{array}$ &
\end{tabular}

Tabel di atas adalah upaya perbaikan yang dilakukan di lapangan dari sembilan proses yang ada di departemen Painting yang dilakukan melalui proses improvement mulai dari proses pertama yaitu proses cleaning sampai dengan proses ke sembilan yaitu proses finishing yang bertujuan untuk menunjang pelaksanaan perbaikan menggunakan HIRADC agar dapat mengurangi resiko kecelakaan kerja di departemen Painting untuk membuat tempat kerja yang aman dan selamat bagi karyawan.

Setelah dilakukan perbaikan manajemen K3 di Painting menggunakan HIRADC dan perbaikan lapangan, kemudian dibandingkan antara data kecelakaan 2016 dan 2017 yang ada di perusahaan untuk mengetahui dampak perbaikan yang sudah dilakukan.

\section{KESIMPULAN}

Berdasarkan hasil pembahasan yang telah dikemukakan sebelumnya maka disimpulkan bahwa:

a. Pelaksanaan Manajemen K3 di bagian Painting belum maksimal, terlihat dari data tahun 2016 yang masih terdapat kecelakaan di bagian Painting, faktor utama penyebab kecelakaan tersebut adalah faktor kelalaian manusia, untuk itu perlu di lakukan upaya-upaya perbaikan.

b. Upaya perbaikan Sistem Manajemen Keselamatandan Kesehatan Kerja menggunakan HIRADC dengan Identifikasi bahaya, Penilaian resiko dan Pengendalian resiko, dari perbaikan tersebut dapat diketahui bahwa dari sembilan proses atau kegiatan yang ada di departemen Painting, proses yang paling kecil kemungkinan resiko kecelakaannya adalah proses cleaning dan finishing dan proses dengan kemungkinan resiko paling besar adalah proses perawatan sprayboth.

\section{SARAN}

Perusahaan dapat melakukan analisa risiko dengan metode HIRADC untuk Departemen lainnya. sehingga dapat meminimalkan kecelakaan kerja pada Departemen lainnya. 


\section{DAFTAR PUSTAKA}

Bennett. (1995). Manajemen Keselamatan dan Kesehatan Kerja, Jakarta : PT Pustaka Binaman Pressindo.

Depnaker RI. (1970). Undang-undang No. 1 Tahun 1970 tentang keselamatan kerja.Jakarta : Departemen Tenaga Kerja RI.

Ramli, S. (2009).Sistem Manajemen Keselamatan dan Kesehatan Kerja. Jakarta : Dian Rakyat.

Sidoarjo. (2009). Hazard Identification Risk Assessment and Determining Controls, (OHSAS 18001:2008, Clause 4.3.1). 
